\title{
Modelling the long-term dynamics of radionuclides in rivers
}

\author{
A.A. Bulgakov, A.V. Konoplev, V.V. Kanivets ${ }^{1}$ and O.V. Voitsekhovich ${ }^{1}$ \\ SPA "Typhoon", Lenin Av. 82, Kaluga Region, Obninsk 249020, Russia \\ 1 Ukrainian Hydrometeorological Institute, Nauka Av. 37, Kiev 251028, Ukraine
}

\begin{abstract}
A model describing the long-term dynamics of radioactive contamination of rivers was developed. The radionuclide activity concentration in river water is assumed to be directly proportional to the content of the radionuclide exchangeable form in the surface layer of soil on the river catchment. The model input parameter values can be determined independently or estimated using results of the short-term observations. The modelled and measured ${ }^{137} \mathrm{Cs}$ activity concentrations in rivers contaminated as a result of the Chernobyl accident are in good agreement.
\end{abstract}

\section{INTRODUCTION}

For prediction of dynamics of radionuclide activity concentration in rivers either quite sophisticated models (see reviews [1] and [2]) or empirical dependencies are usually used [3-6]. The present-day geophysical models account for the totality of meteorological, hydrological, physical and chemical processes governing radionuclides wash-off from catchments and transport in river systems. Hence a large number of input parameters including spatially distributed ones are required. Many of these parameters can be estimated with acceptable accuracy only by direct measurement or model calibration based on a large body of experimental data. It is therefore time consuming and costly to obtain a reliable prediction using such models. The form of empirical time dependencies is, vice versa, selected without analysis of the mechanisms underlying radionuclides transport on catchments and in rivers. Most of these dependencies are exponential. As the real dynamics of radionuclide activity concentration in rivers does not correspond to the exponential dependence, the values of its coefficients dependent on when experimental data were obtained to be used for their estimation. This places a major constraint on application of such dependencies for the purposes of the long-term prediction. This paper is aimed at deriving and verifying a model that would be as simple as possible, on the one hand, and account for the major processes governing dynamics of radioactive contamination of river water, on the other hand.

\section{MODEL DESCRIPTION}

The model is designed for the long-term prediction and does not cover the initial period when radionuclides deposited on the water surface acts as a major contributor to specific activity of river water. Most probably, the duration of this period does not exceed one year, at least for the rivers flowing through the region which is worst contaminated after the Chernobyl accident. The ${ }^{137} \mathrm{Cs}$ transport by these rivers from May to December 1986 was several tenths of a percent of the total activity of radionuclide deposited on the catchment [7]. The part of catchment taken by river channels in low water periods in the region is estimated at not significantly larger than $0.1 \%$. For example, the length of the river Pripyat and Uzh is 761 and $256 \mathrm{~km}$, and the catchment area is 114300 and $8080 \mathrm{~km}^{2}$ respectively [8]. Assuming that along the whole length of the rivers the width is like in the lower reaches (200 and $50 \mathrm{~m}$ respectively) we derive the upper estimate of the part of catchment taken by the channel: $0.14 \%$ for Pripyat and $0.16 \%$ for Uzh. Thus, the total activity of ${ }^{137} \mathrm{Cs}$ transported during the first several months after the accident is approximately equal or higher the activity deposited directly on the river surface. 
In the following period the radionuclide concentration in river water was determined by its transport from catchment, sorption-desorption and resuspension-sedimentation in the system "water- suspendet matter- bed sediments", as well as dilution by relatively clean groundwater and concentration due to evaporation. With the task limited to the long-term prediction of the mean annual radionuclide activity concentration in river water, the influence of the above processes, except wash-off from catchment, on the activity concentration can be considered as irrespective of time. This influence is described in the model by radionuclide and river-specific multi-annual mean coefficient of proportionality between the rate at which radionuclide is transported into the river with the surface runoff and the mean annual actinity concentration in river water:

$$
C_{w}(t)=K_{r} A(t)
$$

where $C_{w}(t)$ is the radionuclide activity concentration in water $t$ years after deposition on catchmerfit Bq. $\mathrm{m}^{-3} ; K_{r}$ is the proportionality coefficient, $\mathrm{yr}^{-\mathrm{m}^{-3}} ; A(t)$ is the rate of radionuclide wash-off by suffare runoff from catchment $t$ years after deposition, Bq.yr.

Radionuclides can be washed off from catchment in solution and on suspended matter:

$$
A(t)=A_{s}(t)+A_{l}(t)
$$

where $A_{s}(t)$ is the rate of radionuclide wash-off by surface runoff from catchment on suspended matter years after deposition, $\mathrm{Bq} . \mathrm{yr}^{-1} ; A_{l}(t)$ is the rate of radionuclide wash-off by surface runoff from catchmen in dissolved form $t$ years after deposition, $\mathrm{Bq} . \mathrm{yr}^{-1}$.

The quantity $A_{l}(t)$ is determined by mean annual rate of runoff $\left(V, \mathrm{~m}^{3} \cdot \mathrm{yr}^{-1}\right)$ and mean annul concentration of radionuclide in it $\left(C_{R}(t), \mathrm{Bq} \cdot \mathrm{m}^{-3}\right) t$ years after deposition:

$$
A_{l}(t)=V C_{R}(t)
$$

The radionuclide concentration in runoff, in turn, depends on the content of the exchangeable formu radionuclide in the surface soil layer and its distribution coefficient in the system soil-runoff $\left(K_{d}^{R}, \mathrm{~m}^{3} . \mathrm{kg}^{4}\right)$ which is a function of soil sorption properties and runoff chemical composition $[9,10]$.

$$
C_{R}(t)=K_{d}^{R} C_{S}(t) \alpha_{e x}(t)
$$

where $\alpha_{e x}(t)$ is the fraction of the exchangeable radionuclide form in the soil surface layer $t$ years after deposition; $C_{S}(t)$ is the radionuclide concentration in the soil surface layer (Bq. $\mathrm{kg}^{-1}$ ).

The radionuclide concentration in the soil surface layer decreases with time as a result of radioactire decay and vertical migration which for non-arable land is described by the equation of diffusion ant convection [11]. The solution of this equation for $z=0$, where $z$ is the distance from soil surface, takes the form:

$$
C_{s}(t)=\frac{Q}{\sqrt{\pi D_{E} t}} \exp \left[-\left(\frac{u^{2}}{4 D_{E}}+\lambda\right) t\right]
$$

where $D_{\mathbb{E}}$ is the effective diffusion coefficient, $\mathrm{m}^{2} \cdot \mathrm{yr}^{-1} ; \mathrm{u}$ is the effective velocity of convective transport, $\mathrm{m} . \mathrm{yr}^{-1} ; \lambda$ is the radioactive decay constant, $\mathrm{yr}^{-1} ; Q$ is the radionuclide deposition density, Bq. $\mathrm{m}^{-2}$.

Obviously, eq. (5) should include instead of the real deposition density $Q$ the effective deposition density $\varphi Q$, where $\varphi$ is the correction coefficient allowing for non-uniformity of the catchmerit contamination. The thing is that the role, which a specific catchment section plays in formationd radionuclide concentration in the surface runoff entering a river, is dependent on how it is situated with 
respect to the river [12]. If a large part of activity deposited on the catchment sections immediately adjacent to the river, then $\varphi>1$, in the opposite situation $\varphi<1$

The fraction of the exchangeable form of radionuclide in soil included in eq. (4) is determined by physical and chemical characteristics of the atmospheric fallout and its transformation in soil. Review of these processes and methods of their modelling is presented in ref. [2]. If a radionuclide was introduced into the soil as solution or as a part of water soluble particles, dynamics of the exchangeable form is described with a fairly good accuracy by the following equation [13]:

$$
\alpha_{e x}(t)=\alpha_{e x}(\infty)\left(I+\delta t^{0.5}\right)
$$

where $\alpha_{e x}(\infty)$ is the equilibrium fraction of exchangeable form of radionuclide in soil; $\delta$ is the kinetic parameter of fixation, $\mathrm{yr}^{0.5}$.

In the existing models the radionuclide specific activity on suspended matter is related either to the activity concentration in the runoff water phase through the distribution coefficient $\left(K_{d}^{S M}, \mathrm{~m}^{3} \cdot \mathrm{kg}^{-1}\right)$ or the radionuclide specific activity in the soil surface layer through the enrichment ratio $(E R)$ [2]. In the first case, the sorption-desorption equilibrium is assumed to set in quickly and in the second case, vice versa, no sorption-desorption in the system runoff-suspended matter is implied. The reality is, in fact, something in between, in other words both ways of parameterization of the radionuclide specific activity on suspended particles are approximate in a general case. Since no experiments are repcrted in the literature which would provide a means for identifying the predominant mechanism of formation of radionuclide content on suspended particles, selection of one of the methods is rather arbitrary. In this work, we use parameterization through the distribution coefficient, as this makes possible to simplify further calculation. In this case the radionuclide specific activity on suspended particles in surface runoff $\left(\mathrm{C}_{S M}(\mathrm{t}), \mathrm{Bq} \cdot \mathrm{kg}^{-1}\right)$ is related to the concentration of the dissolved form as follows:

$$
C_{S M}(t)=K_{d}^{S M} C_{R}(t)
$$

Considering that the activity washed off on suspended particles is equal to the product of $C_{S M}(t)$ by runoff rate and the mean annual content of suspended particles in it $\left(T, \mathrm{~kg} \cdot \mathrm{m}^{-3}\right)$, the total runoff activity can be written as:

$$
A(t)=C R(t) V+K_{d}^{S M} C_{R}(t) V T=C_{R}(t) V\left(1+K_{d}^{S M} T\right)
$$

By substitution in eq. (1) the right hand side of eq. (8) instead of $A(t)$ and then replacing $C_{R}(t)$ by the right hand side of eq. (4) we get:

$$
C_{w}=K_{r} K_{d}^{R}\left(1+K_{d}^{S M} T\right) V C_{S}(t) \alpha_{e x}(t)
$$

Equation describing the long-term dynamics of $C_{w}$ in each particular case can be derived by substitution in eq. (9) of time dependencies for $C_{S}(t)$ and $\alpha_{e x}(t)$ obtained using appropriate models. For example, if the radionuclide is deposited on catchment primarily in the dissolved and exchangeable forms or as easily soluble particles, $\alpha_{e x}(t)$ in eq. (9) can be replaced by eq. (6). If the surface runoff from the non-arable soils prevails on the catchment, $C_{S}(t)$ as a function of time can be presented by eq. (5). As a result we get:

$$
C_{w}=K R(t)
$$

where $K$ is the constant, Bq.yr ${ }^{0.5} / \mathrm{m}^{3}, K=K_{r} K_{d}^{R}\left(I+K_{d}^{S M} T\right) V \varphi Q \alpha_{e x}(\infty) ; R(t)$ is the function of time, yr -0.5. $R(t)=D_{E}^{-0.5}\left(\pi^{-0.5} t^{0.5}+\delta \pi^{-0.5} t^{1}\right) \exp \left[-u^{2}\left(4 D_{E}\right)^{-1}\right]$

The right hand sides of eqs. (9) and (10) are products of two factors. The first is a combination of constants and milti-years mean values and does not depend on time. As some of these parameters cannot 
be obtained in an independent experiment (for example, $K_{r}$ and $\varphi$ ) and methods for their theortio: calculation are not available, the $K$ value can be estimated only by calibration of the model usic experimental data. For doing this, results of determination of radionuclide concentration in river dun: one or several years can be, probably, sufficient. The second factor is a function of time. Its parametis: can be estimated independently using results of the studies of chemical forms transformation and verti: migration of radionuclides in river catchment soils.

\section{COMPARISON OF THE MODEL WITH EXPERIMENTAL DATA}

The model verification was conducted using the database «RUNOFF» under development within t: subproject $3 \mathrm{c}$ of the French-German Initiative for Chernobyl [14]. Data on the activity concentrations dissolved ${ }^{137} \mathrm{Cs}$ in the rivers Uzh, Teterev and Irpen in the vicinity of settlements Cherevach, Loputki Kozarovichi, respectively, were used. Those activity concentrations for which determination error more than $50 \%$ were discarded. The concentrations measured during one year were averaged. As seasonal distribution was the same for the number of collected samples for all the rivers and for the whit: period for which the data are available, such averaging is legitimate and the derived mean annual actiriti concentrations represent the long-term dynamics of radioactive contamination of river water.

Furthermore, estimates of the function $R(t)$ were derived for each year. In the areas of Cherevat: Loputki and Kozarovichi located $20 \mathrm{~km}$ south and south-east of the Chernobyl NPP, the fraction of in: particles in the fallout was insignificant and the rate of their dissolution in soil was rather high [ij] Therefore, transformation of species can be described by eq. (6). It was also assumed that the major pi: of the radionuclide is transported to rivers with surface runoff from non-arable lands and then the decrese: in its content in the surface soil layer is described by eq. (5). If these two conditions are satisfied, radionuclide concentration in river decreases with time in accordance with eq. (10).

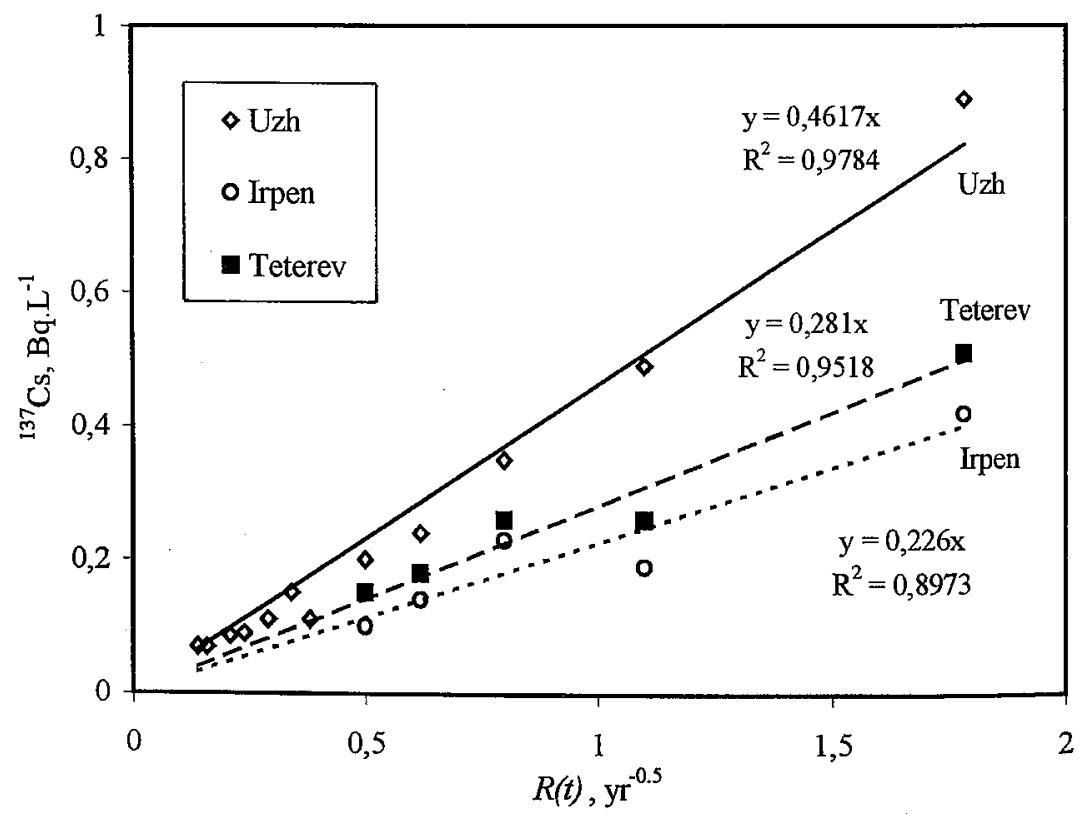

Figure 1. Dependence of the mean annual activity concentration of the dissolved ${ }^{137} \mathrm{Cs}$ on $\mathrm{R}(\mathrm{t})$. 
For estimation of the coefficients of function $R(t)$ in the right hand side of eq. (10) the published values of parameters of migration and chemical form transformation of radiocaesium in the region were used. Ivanov et al. [16], and Bulgakov and Konoplev [17] reported values of the effective diffusion coefficient and the convective transport velocity for ${ }^{137} \mathrm{Cs}$ in soils of the $30-\mathrm{km}$ zone around the Chernobyl NPP. Averaged over several dozens of sampling points the values of $\mathrm{D}_{\mathrm{E}}$ and $u$ are, respectively, 0.18 $\mathrm{cm}^{2} . \mathrm{yr}^{-1}$ and $0.11 \mathrm{~cm} . \mathrm{yr}^{-1}$ according to Ivanov et al. [16] and $0.10 \mathrm{~cm}^{2} . \mathrm{yr}^{-1}$ and $0.28 \mathrm{~cm} . \mathrm{yr}^{-1}$, according to Bulgakov and Konoplev [17]. The values used in this work were the means of these: $0.14 \mathrm{~cm}^{2} \cdot \mathrm{yr}^{-1}$ and $0.20 \mathrm{~cm} \cdot \mathrm{yr}^{-1}$ for $\mathrm{D}_{\mathrm{E}}$ and $u$, respectively. Since mineral sandy loamy and loamy soils are predominant in the region, the value of parameter $\delta$ was taken to be $0.5 \mathrm{yr}^{0.5}$, as was recommended for such soils by Bulgakov and Konoplev [18].

It follows from eq. (10) that the dependence of radionuclide specific activity in river water on $R(t)$ should be described by a straight-line going through the point $R(t)=0$. As can be seen from Fig 1 , this is exactly the way by which the radiocaesium activity concentration decreases with time in all three rivers. This suggests that the hypotheses used as a basis for this model adequately represent the real processes governing long-term dynamics of radioactive contamination of the rivers. Values of the constant $K$ from eq. (10) estimated by the least squares equal $0.46,0.28$ and $0.23 \mathrm{~Bq} \cdot \mathrm{yr}^{0.5} \cdot \mathrm{m}^{-3}$ for Uzh, Teterev and Irpen respectively. These values were used to calculate ${ }^{137} \mathrm{Cs}$ activity concentration in the rivers as a function of time using eq. (10). Fig. 2 illustrates a good agreement between calculated and measured activity concentrations.

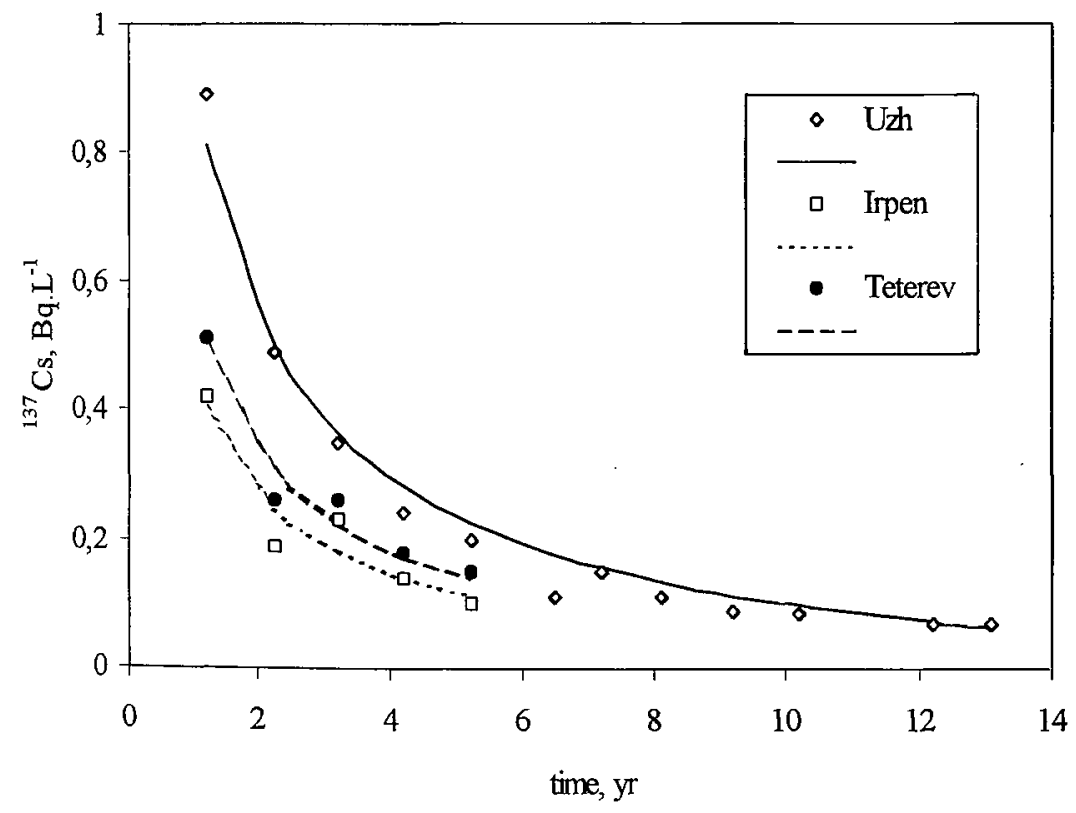

Figure 2. Measured versus modelled ${ }^{137}$ Cs activity concentration in river water. Modelled activity dynamics is given by solid lines, measured values - by points.

In a real situation the experimental data for $K$ value calculation are available only for the initial period of the contamination. However, it seems that this limitation will not significantly contribute into the uncertainty of the long-term prediction. $K$ values calculated using only data obtained in 1987 equal 0.50 , 0.29 and $0.24 \mathrm{~Bq} . \mathrm{yr}^{0.5} \cdot \mathrm{m}^{-3}$ for Uzh, Teterev and Irpen respectively. Differences of these values from those calculated for the whole period of observations do not exceed $10 \%$. This indicates that $K$ value can be estimated with appropriate accuracy using results of the short-term observations. 


\section{References}

[1] Raskob W., Popov A., Zheleznyak M.J., Heling R. Radioecological Models for Inland Water Systems. (FZKA 6089. Forschungszentrum Karlsruhe GmbH, Karlsruhe, 1998).

[2] Konoplev A.V. (Ed.). Transfer of radionuclides by surface runoff. Modelling and parameterisation. FGI Report (IPSN-GRS, Cadarache, 2001, in press).

[3] Smith J.S., Fesenko S.V., Howard B.J., Horrill A.D., Sanzharova N.N., Alexakhin R.M., Elder D.G., Naylor C. Environ. Sci. Technol. 33 (1999) 49-54.

[4] Vozzhennikov O. I.\& Vasil'eva K. I. Rad. Prot. Dosim. 64(1996) 33-36.

[5] Khristyuk B.F. In: Proceedings of Ukrainian Hydrometeorological Research Institute, Issue No 47 (UHRI, Kiev, 1999, in Russian) pp. 184-188.

[6] Vetrov V.A., Alexeenko V.A. Meteorology and Hydrology, 1992, No 11, $21-27$ (In Russian).

[7] Borzilov V.A., Novitsky M.A., Konoplev A.V., Voszhennikov O.I., Gerasimenko A.C. Rad. Prot. Dosim. 50(1993), No. 2-4.

[8] Water Resources and Water Budget of the USSR Area (Hydrometeorological Publishing House, Leningrad, 1967, in Russian).

[9] Bulgakov A.A., Konoplev A.V., Popov V.E. Prediction of ${ }^{90} \mathrm{Sr}$ and ${ }^{137} \mathrm{Cs}$ behaviour in the soil-water system after the Chernobyl accident (Borzilov V. A., Kryshev I.I., Eds. Ecological and Geophysica! consiquencies of nuclear accidents. Gidrometeoizdat, Moscow, 1992, in Russian), pp. 21-42.

[10] Bulgakov A.A., Konoplev A.V., Scherbak, Yu.V. Shveikin. Experimental study and prediction of dissolved radionuclide wash-off by surface runoff from non-agriculcural watersheds. In: NATO Advanced Research Workshop on Contaminated Forests, Kiev, Ukraine, 27-31 May 1998, Linkov I. and Schell W.R., Eds, (NATO ASI Series 2- Kluwer Academic Publishers, Dordrecht, 1999) pp. 103-112.

[11] Clark J. The mathematics of diffusion. (Oxford University Press, London, 1975).

[12] Novitsky M.A., Nikitin A.I. Rad. Prot. Dosim. 64(1996) pp. 29-32.

[13] Bulgakov A.A., Konoplev A.V. Geochemistry International (Moscow), 39(2001) 191-195.

[14] Konoplev A.V., Ed. French-German Initiative for Chernobyl. Sub-Project SP3c: "Runoff in an agricultural and natural environment". Progress report No 5. (SPA "Typhoon", Obninsk, 2001).

[15] Konoplev A.V., Bulgakov A.A. Transformation of ${ }^{90} \mathrm{Sr}$ и ${ }^{137} \mathrm{Cs}$ speciation in soil-water system. Atomic Energy, v. 88(2000), No 1, 55-60 (in Russian).

[16] Ivanov Yu. A., Kashparov, V.A., Levchuk, S.E., Zvarisch, S.I. In: Prister B.S., Ed. Problems of Agricultural Radiology. (Ukrainian Research Institute of Agricultural Radiology, Kiev, 1996, in Russian) pp. 18-29.

[17] Bulgakov A.A., Konoplev A.V., Shkuratova I.G., Russian Soil Sci., 1999, No. 9, 1149-1152 (In Russian).

[18] Bulgakov A.A., Konoplev A.V. Russian Soil Sci., 2001, in press. 